\title{
Mind the gap: gender disparities still to be addressed in UK Higher Education geography
}

Article

Accepted Version

Maddrell, A., Strauss, K., Thomas, N. J. and Wyse, S. (2016) Mind the gap: gender disparities still to be addressed in UK Higher Education geography. Area, 48 (1). pp. 48-56. ISSN 1475-4762 doi: https://doi.org/10.1111/area.12223 Available at https://centaur.reading.ac.uk/70271/

It is advisable to refer to the publisher's version if you intend to cite from the work. See Guidance on citing.

To link to this article DOI: http://dx.doi.org/10.1111/area.12223

Publisher: Wiley

All outputs in CentAUR are protected by Intellectual Property Rights law, including copyright law. Copyright and IPR is retained by the creators or other copyright holders. Terms and conditions for use of this material are defined in the End User Agreement.

www.reading.ac.uk/centaur

\section{CentAUR}


Central Archive at the University of Reading

Reading's research outputs online 


\section{Mind the gap: gender disparities still to be addressed in UK Higher Education Geography}

\begin{tabular}{|r|l|}
\hline Journal: & Area \\
\hline Manuscript ID: & AREA-RP-Jan-2015-0010.R1 \\
\hline Manuscript Type: & Regular Paper \\
\hline Keywords: & gender, survey, United Kingdom, Higher Education, geography \\
\hline & $\begin{array}{l}\text { This paper evidences persistent gender inequalities in UK Higher Education } \\
\text { Geography departments. The two key sources of data used are firstly, } \\
\text { Higher Education Statistics Agency (HESA) data for staff and students, } \\
\text { which affords a longitudinal response to the McDowell (1979) and McDowell } \\
\text { and Peake (1990) surveys of women in UK Geography higher educational } \\
\text { departments; and secondly, a qualitative survey of the UK Higher } \\
\text { Education Geography community undertaken in 2010, that sought more } \\
\text { roundly to capture respondent reflections on their career, their choices, } \\
\text { status and experiences. Findings show that although the gender gap is } \\
\text { closing within HE geography in the UK there are significant ongoing gender } \\
\text { disparities. . Therefore, the paper argues that the long and demanding } \\
\text { process of reducing gender inequalities (alongside other, equally vital } \\
\text { intersectional inequalities) requires continued commitment. Furthermore, } \\
\text { respondents evidence the cost of these inequalities: enablers and barriers } \\
\text { to job security and career progression can have long term impacts on the } \\
\text { quality of life, financial security and affect personal life decisions. In recent } \\
\text { years the UK based Athena Swan and Gender Equality Charter Mark } \\
\text { agendas have prompted universities to address gendered disparities and } \\
\text { the authors note a changing zeitgeist. However, the survey findings point } \\
\text { to the need for sustained leadership within geography departments to } \\
\text { address the day-to-day gender - and other - inequalities experienced in } \\
\text { the workplace. }\end{array}$ \\
\hline
\end{tabular}




\section{Abstract}

This paper evidences persistent gender inequalities in UK Higher Education Geography departments. The two key sources of data used are firstly, Higher Education Statistics Agency (HESA) data for staff and students, which affords a longitudinal response to the McDowell (1979) and McDowell and Peake (1990) surveys of women in UK Geography higher educational departments; and secondly, a qualitative survey of the UK Higher Education Geography community undertaken in 2010, that sought more roundly to capture respondent reflections on their career, their choices, status and experiences. Findings show that although the gender gap is closing within HE geography in the UK there are significant ongoing gender disparities. . Therefore, the paper argues that the long and demanding process of reducing gender inequalities (alongside other, equally vital intersectional inequalities) requires continued commitment. Furthermore, respondents evidence the cost of these inequalities: enablers and barriers to job security and career progression can have long term impacts on the quality of life, financial security and affect personal life decisions. In recent years the UK based Athena Swan and Gender Equality Charter Mark agendas have prompted universities to address gendered disparities and the authors note a changing zeitgeist. However, the survey findings point to the need for sustained leadership within geography departments to address the day to day gender - and other - inequalities experienced in the workplace.

\section{Key words}

gender, United Kingdom, higher education, geography Athena Swan 


\section{Introduction}

The Athena Swan agenda, established by Higher Education Funding Council for England (HEFCE) in 1999 to combat underrepresentation and promote the career progression of women in science in UK universities, has changed the way gender equality is being addressed in some geography departments and units. The Athena Swan award, and the more recent (now merged) Gender Equality Charter Mark for nonscience subjects, is awarded by HEFCE's Equality Challenge Unit to universities and departments demonstrating strategies to combat gender inequalities and create positive working environments (Equality Challenge Unit, 2014). This unprecedented interest in gender equality is to be welcomed given the need to address systemic inequalities evidenced since the first numerical survey of women in higher education geography undertaken by Linda McDowell (1979) and more recently by the International Benchmarking Review of Human Geography, which described UK geography’s intellectual work as world-leading, but identified gender and minority underrepresentation as key shortcomings within the discipline (ESRC 2013, 24). Despite burgeoning growth in feminist scholarship within geography, sparse attention has been given directly to women's position in UK HE geography in the more than twenty years since McDowell and Peake's (1990) follow-up survey. McDowell brought feminist methodologies, gender-based power relations, and the "difference gender makes" in academic geography to the fore (see McDowell 1990, 400; McDowell, 1992). These were complemented by UK-focused studies on gendered degree results (Chapman 1995, with response by Bondi 1996), gendered postgraduate student participation (McKendrick 1996), gendered participation in fieldwork and physical geography (Maguire 1998; Dumayne-Peaty \& Wallens 1998; Bee et al 1998; Madge \& 
Bee 1999; Bracken \& Mawdsley 2004) and the gender gap in the British geographical canon (Maddrell 2009; 2012). In recent years the contemporary gender (im-)balance in UK HE geography has been most directly addressed by Crang's account of 'Malestream Geography' (2003). Internationally, the issue has been addressed in the US (Professional Geographer (2000) and Brinegar (2001)); Australia (Klocker and Drozdzewski (2012) and Johnson (2012)); Spain and Catalonia (Garcia-Ramon and Pujol (2004) and Pujol et al (2012)); and in a comparison of Europe, the East and North America (Monk et al 2004).

Importantly, historic inequities have been set in the context of increasing neoliberalisation of today's HE sector. Although small, compared to the broader literature on work-life balance (WLB) in geography, a body of work is emerging which addresses problems of intensification, the rise of 'audit' cultures, and corporatism within HE, alongside analysis of variegated WLB issues affecting 'core' faculty versus temporary, part-time and contract staff (Ni Laoire \& Shelton 2003; Dowling 2008); processes which are inflected by gender in complex ways. Feminist geographers have documented how attempts to balance these demands are associated with 'fractional' working among tenured and permanent faculty - mostly women. Birnie et al's (2005, 255 ) important discussion of fractional working, highlighted how such arrangements can challenge "the traditional white masculinism of the discipline", but can also produce an "altered balance of power" in which fractional faculty are both marginalised and unduly obligated. Yet faculty with permanent fractional contracts are nonetheless privileged when compared with many adjunct, sessional and contract workers. In the face of a relative paucity of UK data with which to explore how gender, social location and identity (Madge and Bee 1999) shape the subject positions of geographers across 
these shifting landscapes of academia, this paper provides a statistical overview and introduces key narratives from qualitative survey responses.

For UK geographers, the McDowell (1979) and McDowell and Peake (1990) studies provided a baseline against which to judge steps towards gender equality in geography. In 2010 this follow-up study was undertaken by the authors under the auspices of the Women and Geography Study Group of the Royal Geographical Society (with the Institute of British Geographers), renamed the Gender and Feminist Geographies Research Group in 2013. It sought to update statistical data on gender representation within geography by analysing Higher Education Statistics Agency (HESA) data for staff and students alongside responses collected in a 2010 qualitative survey of those studying and working in UK HE geography.

Survey respondents included women, men and transgender contributors. The decision to widen the survey beyond women was in no way a marginalisation or depoliticisation of their experiences of inequality in the workplace. Rather, it was hoped that by giving all individuals the opportunity to reflect on the gendered politics of the workplace, the survey would help produce contextualised and fine grained understandings of women's position in HE geography departments, the relational nature of gender, and other gendered experiences and positionalities that have not previously been identified in subject-based commentaries. This survey presented an opportunity to open up a productive space for the discussion of gendered identities and experience within the HE workplace.

\section{The representation of women in geography: the same old story?}


When McDowell (1979) and McDowell and Peake (1990) mapped the presence of women students and staff in geography departments across the UK, they expressed concern for the attrition of women over the career course from undergraduate to $\mathrm{PhD}$ study and in the transition from postgraduate study to academic employment. The data in Table 1 show that the gender balance has improved significantly over time for both undergraduate and postgraduate students, with female students now making up half or more of the HE geography population; a trend that should continue given geography's close to equal numbers of males and females studying geography at A-Level (Joint Council for Qualifications, 2014).

\section{[Note: Insert Table 1 here or nearby]}

The proportion of women $\mathrm{PhD}$ students in geography has grown from 31 per cent (fulltime students) in 1978 to 50 per cent in 2012/13 (see Table 1). This trend appears to have contributed to more women making the transition from $\mathrm{PhD}$ to academic employment, although the gains have been modest in recent years. While women did not constitute half of researchers and lecturers in 2007/8 (44 per cent for the two categories combined), they are better represented among research and teaching assistants in 2012/13 (55 per cent).

The data for mid and late career grades (senior lecturers and researchers, readers, professors) shows that early-career imbalances in the 1970s and 1980s have carried through a legacy of ongoing underrepresentation of women in senior posts, which echoes the whole UK HE sector (see Universities UK 2013; Grove 2013a and 2013b). The most significant gain has been the proportion of women geography professors, rising from 4 per cent in 1978 to 21 per cent in 2012/13. While this shift is a testament to women's intellectual and managerial leadership contributions to geography, in many 
cases in the face of gender and other equalities within departments or institutions, as well as the growth of the UK professoriate in recent years, the fact remains that almost four out of five geography professors are men.

A view of the gender disparity experienced by women pursuing a career in UK geography between 1979 and 2012/13 is presented in Figure 1, which approximates two possible career timelines from the longitudinal data of the various studies. Series 1 approximates people studying as undergraduates in 1978 progressing to professor in 2012/13, while Series 2 approximates people studying in 1988 progressing to senior lecturer/researcher in 2012/13. For women advancing their careers on these timelines the most visible change in geography departments appears to have been after 1988, when the proportion of women professors was greater than the proportion of women senior lecturers/researchers (i.e. those feeding into the professoriate) in 1988.

\section{[Note: Insert Figure 1 here or nearby]}

The improving equality between men and women appointed in early-career and middle career stages encourages the view that the gender gap is closing, but wider structural changes in HE geography affect how this data is assembled longitudinally and our confidence in how quickly this is happening.

When comparing the two previous studies and more recent HESA data in Table 1, the number of reported geography departments doubled from 34 responding departments in 1978 (a response rate of 83 per cent; 41 departments in existence (McDowell 1979)) to 69 in 2008. The number of academic staff across all grades almost tripled. This expansion contributed significantly to the changing face of HE geography in the UK, as did the relative growth of the proportion of academics in senior grades, especially the professoriate. Consequently, widespread changes in the academic grade structure and 
the HESA staff reporting structures make it difficult to compare precisely over time, e.g. not all institutions report staff within nationally recognised structures or with adequate grade differentiation, so some senior grades may be under-reported, such as the introduction of Associate Professors and relative decline of Readers.

The definition of geography itself is changing too. Domosh (2014) highlights the many nomenclatures and rationales in the rebranding and restructuring of geography departments in the United States, and a similar pattern can be observed in the United Kingdom. Geography departments variously find themselves in science, technology, social science and arts faculties, colleges and schools as universities attempt to codify their cross-disciplinary interests (Hall et al, 2015), and geographers themselves are similarly 'out of place' (Wainwright et al, 2014). The HESA student subject codes and staff cost centres data are transient too, with changes to staff cost centres between 2007/08 and 2012/13, no clear relationship between student subject codes and staff cost centres, and the inclusion of staff and students outside geography departments in both data.

Even allowing for these caveats, the trend towards greater gender equality in senior grades since the 1990's is demonstrative of a step change in career progression opportunities for women in geography. But whether these changes are due to the rapid expansion and change of the higher education sector itself, or changes within individual departments or institutions is an open question. A national view of the gendered balance of staff in geography can mask the progress towards equality, or on-going inequalities within individual departments. It also, necessarily, masks or elides more complex histories and stories of institutional change and personal trajectories - as Domosh and Bondi (2014) remind us, academic 'success' often hides contingent outcomes, and is narrated in ways that are themselves gendered. 
This paper now turns to the qualitative survey and its findings in more detail, in order to shed light on these questions.

\title{
3. Attending to the 'gap': binding cultures of equality into the ethos and ambience of UK Geography
}

\author{
"at present there are no formal reports on issues such as women geographers' \\ experiences of discrimination, membership of professional organisations, role \\ models, career progression or salary levels .... It is difficult to be certain exactly \\ what does stop women geographers reading for postgraduate degrees as they \\ have never been asked..." (McDowell and Peake 1990, 20, 25).
}

The need for a qualitative approach to understanding the uneven representation of women at different levels, in different sub-disciplines, and across pay grades within UK geography was addressed by the 2010 survey, which asked a series of questions about experience of career choice and progression. The survey was widely advertised on UK HE geography mailing lists and networks and 360 respondents completed the survey. Of those, 253 were working or studying at a UK HE institution at the time of the survey, with others seeking work, working outside academia, taking a career break or working outside the UK. Respondents were 65 per cent female, 33 per cent male and 1 per cent other gender; more than 70 per cent of respondents were post-PhD, with all career stages represented, including 11 professors. The survey explicitly asked respondents to explore the dynamics of gender in relation to their career progression; responses also highlight other inequalities linked to social relations within the workplace, offering insight into the ongoing dominance of white, heteronormative and ableist cultures within UK HE geography (Horton and Tucker, 2014), and challenges 
faced by working outside or on the fringes of the academy. These rich data will be further discussed in a subsequent paper, but it is important to signal a number of key issues as context to the statistical findings above and their interpretation, namely: discrimination and bullying, marginalisation, employment precarity, caring responsibilities and departmental cultures.

The survey allowed people who had experienced significant discrimination and bullying to highlight their troubling situations. Under the UK Equality Act 2010, it is unlawful to discriminate against anyone because of his or her protected characteristics, for example age, sexuality, religion or belief (Gov.uk, 2014a). This Act also identifies the forms in which discrimination can come (indirect, direct, harassment and victimisation). The UK Government recognise bullying and harassment as 'behaviour that makes someone feel intimated or offended', however bullying behaviours are not against the law, unless the 'unwanted behaviour' is related to a protected characteristic (Gov.uk, 2014b). Bullying can be construed as practices that may be related to discrimination, but may more broadly reflect the default mode of an individual's interaction with colleagues, or ambient culture in certain workplaces, which is not directly targeted at people with protected characteristics. Departments need to be aware of both dimensions of this problem. Some of the respondents had experienced positive resolution of these issues within the workplace; others were driven to breakdown or moved jobs to escape it, as exemplified by the following quote:

In my last job the default mode of management was bullying. The bullying made me really miserable just ate away at me. I watched [multiple] colleagues have breakdowns and just wondered when the same would happen to me. It made me desperate to leave my job and I would have left academia to get away from it - if 
that had happened it would have killed my career. At home it just meant I was always miserable and hard to be around but my partner put up with it. (Female 5, 35-44 years)

Those living with situations identified as indirect bullying reflected on the use of daily practices of avoidance as a coping strategy:

[I experienced] bullying by an administrative person in the department who talks negatively about me... It has affected the way I work. I have avoided to be in the department in certain periods of time and have worked from home or the library. (Female 351, 26-34 years)

Owing to the relative flexibility of the academic workplace, such tactics of avoidance were a common feature of the ways in which those living with bullying/discrimination handled the situation.

Respondents also recorded 'everyday' discrimination: the small, normalised acts of exclusion that are often absorbed by those who experience them as a part of the everyday ethos and ambiance of a workplace. Respondents were often ambivalent about labelling these everyday acts as 'discrimination' per se, but felt strongly that it marginalised or excluded them from equality in the workplace. A common example of an everyday act of exclusion as a consequence of departmental ethos was identified as a result of assumptions that women should assume more pastoral roles, or would be more likely to receive teaching related administration, rather than research management or leadership (see Maddrell 2009 for longstanding evidence of this gendered practice and McDowell 1990 on how department culture can influence forms of stereotyping or harassment). The following quote exemplifies the process, assumptions and cumulative negative impact of such everyday sexism: 
Just the subtle comments or tongue-in-cheek jokes of less enlightened colleagues... jokes about their discomfort being around 'so many women', or jokes about how useless they are at doing things women might be better at doing (like counselling students, etc.). It's the kind of silly stuff that just shouldn't be said but is anyway. It's just frustrating! Some of it can get shrugged off, some of it less so. (Female 48, 35-44 years)

Other examples of quotidian exclusion linked to the ambience of a department included male respondents reflecting on the long-term advantages of sharing the same social lexicon or interests, for example sporting or other (normalised male orientated) activities that resulted in enhanced social capital within the profession:

Yes, I think I had an advantage during undergrad \& grad studies. We (other male students) would play [sport] \& go for drinks with our male profs which helped us establish informal and cordial relations with the male faculty. This came in handy for marking \& research jobs as well as references for grants. I still consult with a number of my profs from undergrad, one or two I still consider mentors. I think my gender helped me to establish this social capital. To this day I tend to get along better with male colleagues, supervisors and professors. (Male 278, 26 to 34 years old)

Thus, social activities can be simultaneously inclusive and exclusive. Shared cultures of drinking (during fieldwork or in the pub) were likewise identified as an exclusionary practice for those who were not included, were made to feel they didn't 'fit', or were barred from participation by other commitments. The observations of respondents resonated with debates in geography about, for example, masculinist cultures of fieldwork (Rose 1993; Sundberg, 2003; Mawdsley and Bracken, 2004); and ways of thinking (Longhurst and Johnston, 2014; Mott and Roberts, 2014). There are also 
obvious implications for those whose religious observance bars them from social spaces and practices of alcohol consumption, as well as those who may have alcohol-related problems. The implications of informal processes of exclusion relate to multiple sites and practices of academic subject formation, and are of particular relevance in an era of increased international mobility of faculty and students in which significant barriers still exist to the full participation of women of colour (Mahtani 2004).

The twin issues of workload intensification, and feelings of insecurity and precarity of employment, were recurrent themes within the responses (see Strauss et al 2013).

Permanent staff highlighted stress as a result of increasing teaching, administration and research workloads (especially grant applications and publishing, key performance indicators in the government's Research Excellence Framework evaluations):

Some senior staff fail to realise or comprehend how difficult it is to work as a junior member of staff at this university and they dump work on us at will. As such this is the first time I have worked somewhere where with more seniority comes less responsibility. This sort of bullying is insidious in universities. (Male $133,35-44$ years)

On the other hand, echoing Birnie et al (2005), researchers on temporary and fixed term contracts expressed feelings of precariousness and insecurity - some of whom felt they had no chance of ever securing a full-time permanent academic role with possibilities for progression:

It is not my gender, but rather the gendered nature of temporary contract research status which I feel is holding me back in career opportunities and responsibilities. Contract research staff are not always treated as full members of staff in some universities - I do not have access to institutional research funds or 
mentoring schemes, no opportunity to take on departmental responsibilities which may help me to get involved in the core activities of my department. ... I work on a research team as the junior member and find myself having to do menial tasks, and feel that my work is not given sufficient credit in attributing authorship in joint publications. (Female 262, 26-34 years)

Not only are women over-represented in junior posts, these jobs have undergone a process of feminization, most notably in their short-term nature. The responses indicate that negative experiences of intensification and workload were commonly experienced and that particular stages in the career course (transition from temporary or fixed-term to permanent roles, and mid-career progression in particular) and personal circumstances (caring responsibilities, home situations and work/life balance choices) intensified the day to day stress and (in)ability to respond to the pressures of the neoliberal(ising) university. In some cases supportive managers facilitated satisfactory part time contracts for those with caring responsibilities, but others echoed Birnie et al's (2005) description of being made to feel both invisible and a particular sense of obligation for the 'dispensations' afforded to them, and/or pressure to overwork.

The survey also shows that respondents were taking on a variety of personal caring roles, of particular significance due to pressure on academics to work beyond contracted hours. While parenting responsibilities for pre-school children were highlighted, other caring responsibilities identified were: children of all ages, partners; elderly and/or infirm parents and neighbours; friends experiencing challenges or long-term illness. Respondents indicated that their caring roles required different intensities of care at different times, with wide-ranging impacts on work/life balance, regardless of seniority: 


\begin{abstract}
Very exhausting responsibilities for elderly members of the family (now mercifully over, through death and residential home). This almost brought me to a complete nervous breakdown. I still take the medication, for fear of not knowing what might happen if I stopped. I really do not want to go back there. How I got through teaching, admin, [working in senior management]... all of that in the worst months is beyond my comprehension. I never took a day off sick in my whole career (contrary to the advice of my GP). (Male 116, 65+ years)
\end{abstract}

Although UK Universities are bound by the 2014 UK Flexible working law (Gov.uk, 2014c), the ability and inclination of an employee to navigate these with confidence will depend on the institutional policies and the leadership of their department.

While the survey reported women and men undertaking caring responsibilities, many women in particular feel the need to downplay these responsibilities for fear of being seen as less committed to their work, whereas men appear to seek (and receive) recognition for caring roles. The fact that a number of women respondents referred to the impossibility of combining academic work and a family life, while this issue was not raised by men, suggests that women still anticipate having to sacrifice career for childrearing, or vice versa, in a way that men do not. These women reported the implicit and explicit message that children and academic progression did not mix.

On several occasions I have been told by senior female academics that if a woman has children she is signalling that she is not serious about an academic career! There are a lot of things that are said 'under the radar' that affect the chances of an academic career. (Female 157, 26-34 years) 
Despite advances in work practices around maternity leave and a smaller gender gap in earlier career stages, comments such as this indicate a sense of conflict in younger female academics, who perceive an academic career as incompatible with starting a family. As Crang $(2007,511)$ noted: "Balancing demands to be a carer and have an academic career raises an unequally gendered set of issues".

For scholars familiar with the politics of intersectional identities and practices of exclusion/inclusion, the findings of the survey may not be surprising. Indeed, in some ways the results echo the title of the McDowell and Peake (1990) paper 'same old story?'. Crucially, responses made visible the overt inequalities in the workplace that still endure, for example, the difference between legal entitlement to maternity leave or flexible working arrangements and departmental attitudes to such entitlements in practice, and, reiterating McDowell's (1990) findings, the significance of less tangible factors such as departmental culture serving to privilege some and marginalise others. Furthermore, testimonies indicate a systemic issue around the way in which departmental ethos can enable and/or perpetuate a culture that undermines equality, at the loss of physical and mental wellbeing and the intellectual, social and emotional capital of those who are excluded.

\section{Conclusion}

Regardless of some structural differences in the longitudinal statistical data, the survey and study show four clear findings.

First, it evidences growth of the number of women appointed as professors and growing gender equality within some departments, but persistent gender disparities in UK geography as a whole. 
Second, the changes required to reduce gender inequalities within UK universities represent a long and demanding process. Discipline-wide and departmental 'ethos' and 'ambiance' can supports or undermine efforts to secure equality. Good practice highlighted by respondents included attentiveness to social relations and a wider ethos of equality within departments, and the use of varied and sustained strategies to address inequalities.

Third, respondents were acutely aware of key career transition points, and both enablers and barriers to their progression. Much has been written on the glass ceiling preventing mid-career moves to senior roles, but the stone floor keeps people, notably women, stuck in the lower echelons of academia (Heward and Sinclair Taylor, 1995). This can have long-term impacts on quality of life and personal life decisions such as parenthood, as well as penalising individuals financially with lower salaries now, which map on to lower pensions in retirement, resulting in significant gender disparities in lifetime income.

Fourth, the advent of HEFCE's Athena Swan and Gender Equality Charter Mark initiatives suggest a changing zeitgeist. However, evidence of early-career precarity, workload pressures, stress-related illness, discrimination, harassment and bullying in this survey highlight grave concerns about institutional cultures and the wellbeing of academics in geography, which can be linked to broader narratives of job insecurity, stress and (lack of) well-being in the wider university sector, as evidenced by The Guardian's article on 'Dark Thoughts, mental illness on the rise in academia' (2014).

This paper has made visible ongoing gender inequality in the geography workplace and challenges assumptions that geography has successfully tackled the 'gender problem'. The collective personal testimony of respondents evidence and illuminate the day-to- 
day experiences of inequality in departments, which statistical data analysis alone cannot speak to. Together this data should inform our collective understanding of inequality and exclusion, and our mutual responsibility to work towards equality in the workplace. Heads of Departments and their supporting senior colleagues have a particular responsibility in leading change to address gender inequalities and the direct and indirect discrimination that is frequently associated with such inequalities. To conclude, we call for the discipline of geography as a whole to 'mind the gap' and call on all departments to work towards meeting the gender equality requirements through Athena Swan and Gender Equality Charter Mark accreditations. We see this as integral to, rather than separate from, a broader agenda that addresses other significant areas of inequality, e.g. sexuality, race and dis/ability, through the UK Race Equality Charter Mark now being trialled and the Stonewall (2013) Top 100 Employers list. However, policy alone is rarely sufficient, and indirect factors such as departmental ethos and ambiance play a significant role in fostering and maintaining cultures of equality. There still needs to be a greater and more systemic integration of 'formal' and 'academic/theoretical' approaches; that is, of structured programmes for addressing inequality, and more difficult, contentious and reflexive debates about how geography operates as a discipline and how academic subjects are shaped under particular conditions. The latter includes confronting, as Valentine et al (2014) remind us, the 'ordinary sexism' that patriarchy and the gendered division of space - as well as the gender division of labour - produce and reproduce. There are structural and interpersonal issues that demand both policy and praxis of equality. Ultimately, departments working towards an inclusive ethos and ambiance will constitute healthy working environments, which are simultaneously an investment in the long term wellbeing of staff, and therefore the quality of student experience. 
References

Brinegar S 2001 Female Representation in the Discipline of Geography Journal of Geography in Higher Education 25:3 311-320

Crang M 2003 Malestream geography: gender patterns among UK geography faculty Environment and Planning A 35:10 1711-1716

Crang M 2007 Flexible and Fixed Times Working in the Academy Environment and Planning A 39:3 509-514

Domosh M 2014 What's in a Name? The Renaming and Rebranding of Geography Departments (http://news.aag.org/2014/04/whats-in-a-name-the-renaming-andrebranding-of-geography-departments/) Accessed 4 August 2014

Domosh M and Bondi L 2014 Remembering the making of Gender, Place and Culture Gender, Place \& Culture 21:9 1063-1070

Dowling R 2008 Geographies of identity: labouring in the 'neoliberal' university Equality Challenge Unit 2014a Aligning Athena SWAN and the gender equality charter mark (http://www.ecu.ac.uk/equality-charter-marks/charter-marksexplained/athena-swan-and-gender-charter-mark) Accessed 10 March 2015 ESRC 2013 International Benchmarking Review of Human Geography (http://www.esrc.ac.uk/research/evaluation-impact/research-evaluation/internationalbenchmarking/uk-human-geography.aspx) Access 1 December 2014 Gov.uk 2014a (https://www.gov.uk/discrimination-your-rights/types-of-discrimination) Accessed 8 October 2014 
Gov.uk 2014b Workplace bullying and Harassment (https://www.gov.uk/workplace-

bullying-and-harassment) Accessed 8 October 2014

Gov.uk 2014c Flexible Working (https://www.gov.uk/flexible-working/overview)

Accessed 8 October 2014

Grove J 2013a Gender survey of UK professoriate, 2013 Times Higher Education 13

June 2013 (http://www.timeshighereducation.co.uk/news/gender-survey-of-uk-

professoriate-2013/2004766.article) Accessed 27 November 2014

Grove J 2013b Global Gender Index 2013 Times Higher Education 2 May 2013

(http://www.timeshighereducation.co.uk/features/global-gender-index-

2013/2003517.article) Accessed 27 November 2014

Hall T, Toms P, McGuinness M, Parker C and Roberts N 2015 Where's the

Geography department? The changing administrative place of Geography in UK higher education. Area, 47:1 56-64

HESA Staff Record 20012/13 Higher Education Statistics Agency Limited: Chichester 2014

HESA Staff Record 2007/08 Higher Education Statistics Agency Limited: Chichester 2010

HESA Student Record 2007/08 Higher Education Statistics Agency Limited:

Chichester 2010

HESA Student Record 2012/13 Higher Education Statistics Agency Limited:

Chichester 2015

Heward, C and Sinclair Taylor A 1995 Women into management workshops: shattering the glass ceiling or raising the stone floor? Journal of Teacher Development $4: 2$ 
Horton, J and Tucker, F 2014 Disabilities in academic workplaces: experiences of human and physical geographers. Transactions of The Institute of British

Geographers 39(1), 76-89

Joint Council for Qualifications 2014 Provisional A Level Results - June 2014 (All

UK Candidates) (http://www.jcq.org.uk/examination-results/a-levels) Accessed 1

December 2014

Klocker, N and Drozdzewski, D 2012 Commentary: Career progress relative to opportunity: how many papers is a baby 'worth'? Environment and Planning A 44:6 $1271-1277$

Longhurst R and Johnston L 2014 Bodies, gender, place and culture: 21 years on Gender, Place \& Culture 21:3 267-278

Maddrell A 2009 Complex Locations. Women's geographical work in the UK 18501970 Wiley-Blackwell/RGS-IBG, Oxford-Chichester

Maddrell A 2012 Treasuring classic texts, engagement and the gender gap in the geographical canon Dialogues in Human Geography 3:2 324-7

Madge C and Bee A 1999 Women, science and identity: interviews with female physical geographers Area 31:4, 335-34

Mahtani M 2004 Mapping Gender and Race in the Academy: The Experiences of Women of Color Faculty and Graduate Students in Britain, the US and Canada Journal of Geography in Higher Education 28:1 91-99

Mawdsley E and Bracken LJ 2004 'Muddy glee': rounding out the picture of women and physical geography fieldwork Area 36 280-286

McDowell L 1979 Women in British Geography Area 11:2 151-154

McDowell L 1982 Report: Perspectives on Feminism and Geography Area, 14:2 175

McDowell L 1990 Sex and Power in Academia Area 22:4 323-332 
McDowell L 1992 Doing Gender: Feminism, Feminists and Research Methods in Human Geography Transactions of the Institute of British Geographers, New Series $17: 4399-416$

McDowell L and Peake L 1990 Women in British geography revisited: or the same old story Journal of Geography in Higher Education 14:1 19-30

Monk J, Fortuijn JD, and Raleigh C 2004 The representation of women in academic geography: Contexts, climate and curricula Journal of Geography in Higher Education $28: 1,83-90$

Mott C and Roberts S 2014 Not Everyone Has (the) Balls: Urban exploration and the persistence of masculinist geography Antipode 46:1 229-245

Ni Laoire C and Shelton NJ 2003 'Contracted out': some implications of the casualization of academic labour in geography Area 35:1 92-100

Progress in Human Geography 32 812-820

Rose G 1993 Feminism and Geography: The Limits of Geographical Knowledge Minneapolis: University of Minnesota Press

Shaw, C and Ward, L 2014 'Dark Thoughts, mental illness on the rise in academia'. The Guardian, Higher Education Network (6th March 2014). http://www.theguardian.com/higher-education-network/2014/mar/06/mental-healthacademics-growing-problem-pressure-university. Accessed 27 November 2014 Stonewall 2013 Stonewall Top 100 Employers 2013 The Workplace Equality Index (http://www.stonewall.org.uk/documents/final top 100 booklet_website version high res_1.pdf) Accessed 8 October 2014

Strauss K, Maddrell A, Thomas N and Wyse S 2013 Internationalisation and the neoliberal university Querelles: Almanac for Women and Gender Studies, Edition 2012 
Sundberg J 2003 Masculinist Epistemologies and the Politics of Fieldwork in Latin Americanist Geography The Professional Geographer 55:2 181-191

Universities UK 2013 Patterns and Trends in UK Higher Education

(http://www.universitiesuk.ac.uk/highereducation/Pages/PatternsAndTrendsInUKHighe rEducation2013.aspx\#.VJFGLCusWOw) Accessed 8 October 2014

Valentine G, Jackson L and Mayblin L 2014 Ways of Seeing: Sexism the Forgotten

Prejudice? Gender, Place \& Culture 21:4 401-414

Wainwright E, Barker J, Ansell N, Buckingham S, Hemming P and Smith F 2014

Geographers out of place: institutions, (inter)disciplinarity and identity. Area 46: 410-

417 
Table I: Number and percentage UK higher education participants who are female; staff by academic grade and students by level of study

Sources: 1978: McDowell 1979 (0.5 values to reflect FTE status); 1988: McDowell \& Peake 1990; 2007/08

HESA Student record (F8: Physical Geographical Sciences and L7: Human and Social Geography); 2007/08:

HESA Staff Record (28: Geography); 2012/13 HESA Student record (F8 and L7); 2012/13: HESA Staff Record (124: Geography and Environmental Studies) ${ }^{1}$. HESA Standard Rounding Methodology was applied to the Staff Record data (shown as Full Person Equivalent, FPE) to prevent the disclosure of confidential or personal information, which may mean that some FPE counts do not sum to the rounded total and percentages calculated on a population of 0 to 52 persons are suppressed, indicated by [..]. Student record subject codes are not precise categories and include students studying related subjects outside geography departments.

\begin{tabular}{|c|c|c|c|c|}
\hline Academic grade & 1978 & 1988 & $2007 / 08$ & $2012 / 13$ \\
\hline \multicolumn{5}{|l|}{ Students } \\
\hline Undergraduate & $42 \%(3194)$ & $44 \%(2872)$ & $49 \%(11311)$ & $50 \%(11925)$ \\
\hline Masters & $29 \%(79)$ & $35 \%(97)$ & $47 \%(1174)$ & $52 \%(1332)$ \\
\hline $\mathrm{PhD}$ - full-time & $31 \%(155)$ & $32 \%(135)$ & & \\
\hline $\mathrm{PhD}$ - part-time & $20 \%(63)$ & $34 \%(59)$ & & \\
\hline $\mathrm{PhD}-$ all & & & $49 \%(629)$ & $50 \%(670)$ \\
\hline \multicolumn{5}{|l|}{ Staff } \\
\hline Research and Teaching Assistants & & & & $55 \%(235)$ \\
\hline Lecturers & & & $38 \%(175)$ & \\
\hline Researchers & & & $49 \%(210)$ & \\
\hline Lecturers and Researchers & & & & $48 \%(315)$ \\
\hline Lecturers and Senior Lecturers & $8 \%(38)$ & $11 \%(58)$ & & \\
\hline Senior Lecturers and Researchers & & & $26 \%(120)$ & $33 \%(305)$ \\
\hline Readers & $6 \%(4)$ & $7 \%(4)$ & & \\
\hline Professors & $4 \%(3.5)$ & $4 \%(5)$ &..$(50)$ & $21 \%(65)$ \\
\hline Other grades & & & $37 \%(90)$ & \\
\hline Other junior grades/administrative & & & & $71 \%(265)$ \\
\hline Other senior grades/managerial & & & &..$(20)$ \\
\hline Total staff (male and female) & 620 & 686 & 1910 & 2745 \\
\hline
\end{tabular}

\footnotetext{
${ }^{1}$ HESA's standard rounding methodologies have been applied. HESA cannot accept responsibility for any inferences or conclusions derived from the data by third parties. GFGRG is grateful to the RGS-IBG for assistance in obtaining HESA data.
} 
Figure 1: Gender ratios of university geography students and teachers, 1978 to 2013

Sources as labelled, see Table 1 for notes; see text for explanation of Series 1 and 2

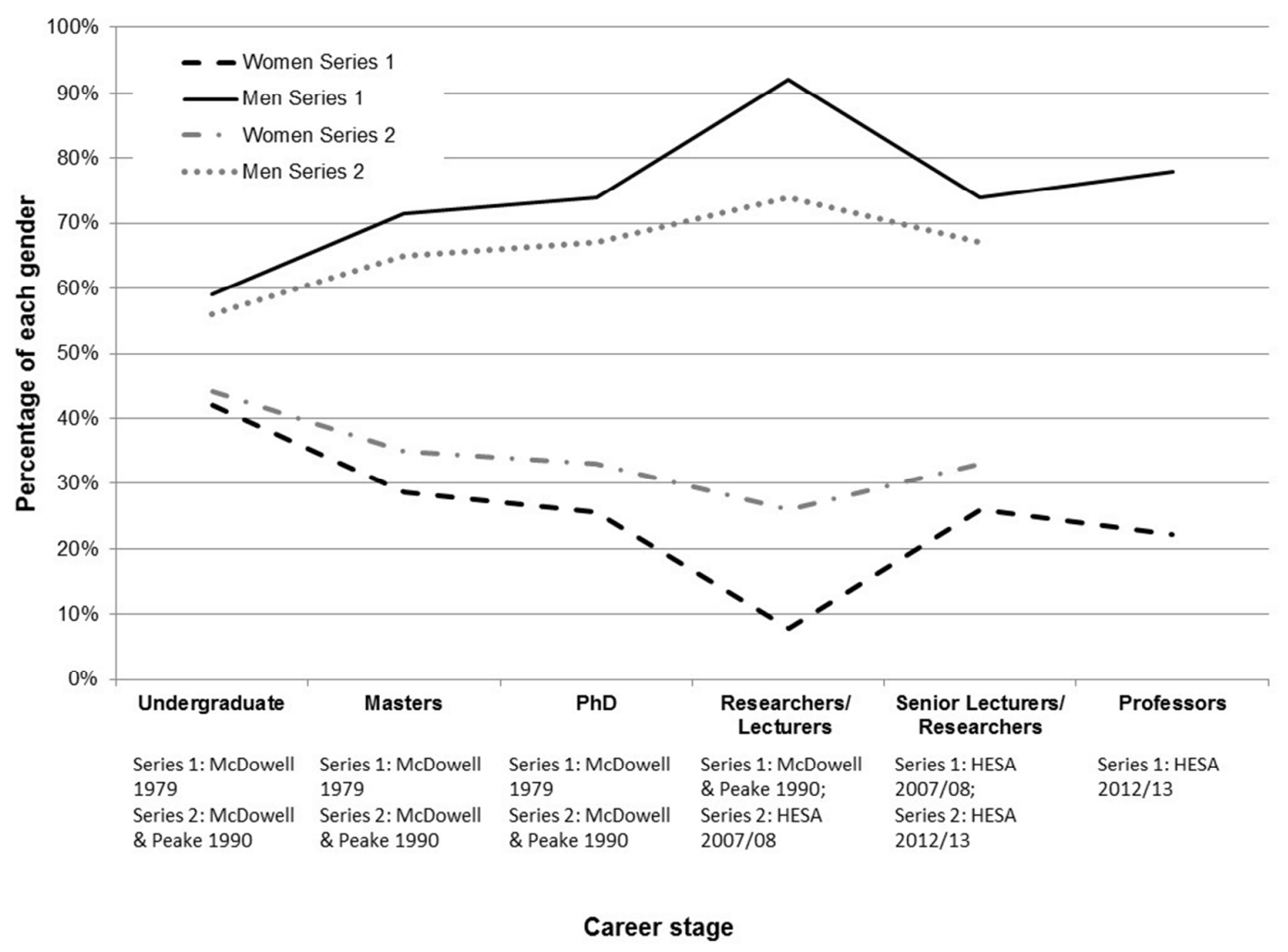

